https://doi.org/10.48009/1_iis_2010_518-524

\title{
ASSESSING BLACKBOARD: STUDENT PERCEPTIONS OF THE ONLINE TOOL
}

\author{
Adnan A. Chawdhry, California University of Pennsylvania, chawdhry_a @ calu.edu \\ Karen Paullet, American Public University System, kp1803@online.apus.edu \\ Daniel Benjamin, American Public University System, dbenjamin@apus.edu
}

\begin{abstract}
Current trends indicate that an increasing number of Universities have been offering online classes without assessing the online learning management tolls from the perspective of the students. It is only when a University understands the benefits and concerns perceived by the student population that they can begin to implement or improve an online education environment that is conducive to a student's learning. This paper provides a quantitative assessment of Blackboard as a tool used for online classes at a small rural Mid-Atlantic university. A survey was distributed to the undergraduate and graduate student population to understand their satisfaction with Blackboard and their perceived benefits / drawbacks of the technology. This survey was based upon a study that was conducted at the University of Denver in 2006. The results of the survey were analyzed to better understand the students' perceptions of this technology and what improvements could be made.
\end{abstract}

Keywords: Blackboard, Online Classes, Distance Education, Learning Management System

\section{INTRODUCTION}

Universities and colleges have attempted to improve the learning techniques and methods used to educate students. Distance learning enables universities to enhance accessibility to larger student populations. Another benefit of online programs and courses is its ability to service students who are unable to physically attend classes on campus. The reasons that students may not be able to attend traditional classes include, but are not limited to, family, location of the campus, cost, employment, or time constraints. Online courses enable students to work at their own schedule while allowing them to balance the demand of their daily lives.

Universities and colleges offer classes via web based learning management systems that provide faculty with the necessary tools to develop and teach courses online. Universities all over the world offer courses online through web based management systems. As of March 2010, one in every four students registers for online courses. With the growing demand for online courses, it is necessary for Universities to provide students with the best learning tools available. For the purpose of this study we will examine student's perceptions of using Blackboard at a Mid-Atlantic University.

\section{LITERATURE REVIEW}

Online education is expanding at a rapid pace. According to a January U.S. News World Report, [3] there were more than 46 million college students taking at least one online course at the end of the 2008-2009 school year. That is a $17 \%$ increase from the previous year. Ninety percent of this new growth comes from traditional schools offering courses online. More and more people use distance learning to complete their degrees in order to compete in today's job market and to advance in their careers.

A study conducted by Hannay and Newvine [4] indicated that students prefer online education because it allows them to balance their life obligations while going to school. The researchers sought to determine why students were interested in distance learning; their survey was completed by 217 students. Twenty percent of the participants chose distance learning because the courses necessary to complete their degrees were only offered at limited times in the brick and mortar campuses but were scheduled more often in the world of online education. Approximately $88 \%$ of students chose distance learning because they had other commitments that precluded them from physically attending courses on campus. The study also indicated that $59 \%$ of students surveyed reported that their grades were higher in distance learning than traditional courses and that $70 \%$ of students preferred online courses. Another interesting finding of the study was that $90 \%$ of students read the textbooks associated with their online courses as compared to just $60 \%$ of students that read the textbooks in traditional courses.

According to Blackboard, [1] students have an educational advantage when using the online tools 
associated with its web-based learning management system. The web-based tools used in Blackboard enhance communication and interaction between class members and faculty through discussion boards, email and chat rooms. By using the online forums, students are able to share their perspectives and experiences while gaining a sense of equality. Instructors are able to accommodate the different learning styles of the students in their assignments, discussion boards, and teaching materials by including video, audio and visual examples. Another benefit is that course materials are always available to students twenty-four hours a day, seven days a week; this allows students to access their education at their convenience Students are able to utilize their time efficiently while maximizing the classroom experience.

An exploratory study conducted by Dorado, et.al. [2] surveyed 146 students to determine the factors that influenced their decision to take online courses. The study examined four key elements that influenced a student's decision to take online courses; the influences were convenience, level of difficulty, effectiveness and social interaction. Convenience was the main factor that influenced a student's decision to take online courses. The social interaction factor resulted in negative ratings.

In their study of the perceptions and uses of the Sakai Learning Management System (LMS), Lonn and Teasley [5] found marked differences in the instructors' and students' perceptions of the benefits and value of LMS components. Seven percent of instructors felt that the LMS improved instructor teaching as compared to just $1 \%$ of the students' that is a sevenfold difference. Also, 39\% of instructors felt that the LMS instructor-to-student communication was beneficial as compared to just $15 \%$ of students. With respect to the components of the LMS, the researchers found that $65 \%$ of the instructors considered announcements to be Very Valuable as compared to just $45 \%$ of students. Additionally, $21 \%$ of the instructors considered Discussion Boards to be Very Valuable as compared to just $13 \%$ of students. An examination of the utilization logs in this study found that students preferred information exchange to interaction between each other. The researchers found that the tools which facilitated information exchange to interaction between instructors and students (Content Sharing, Assignments, Schedule, and Syllabus) were popular; accounting for $95 \%$ of the usage transactions; on the other hand, tolls that facilitated interaction (Chat, Discussion Board, and Wiki) accounted for just $5 \%$ of the total utilization [5]. One possible reason is that just $21 \%$ of instructors and $13 \%$ of students considered Discussion Boards to be Very Valuable. One possible reason for the low utilization of the tools that facilitated interaction is that students are focused on getting the job done and completing the course; in which case, the are inclined to just do the basic interaction necessary to get the desired grades. This study demonstrates that instructors and students tend to value the benefits and the components of the LMS very differently.

The Center for Teaching and Learning's Courseware Faculty Advisory Board (CFAB) completed a study on how Blackboard was being utilized at the University of Denver. The Board [6] distributed a survey via email to approximately 8,000 students who had at least one instructor who utilized Blackboard to assist with courses. A total of 1,821 students completed the survey. Approximately $51 \%$ of students reported using Blackboard in $75 \%$ of their classes. The students reported that they found the weekly announcements and grade book to be the most useful tools in Blackboard. Nearly $90 \%$ of students found Blackboard to be an excellent webbased tool. Fewer than $2 \%$ of students reported having a bad experience with Blackboard.

The number one reason that students from the University of Denver study liked Blackboard is that they have access to the course materials at all times. The participants also perceived that there was a strong communication level with their instructors. Other benefits included access to grades, improved class discussions, and the ability to view assignments. Approximately $82 \%$ of students prefer courses that utilize Blackboard or other web-based tools compared to just $10 \%$ who do not. A relatively small number of students, $3.5 \%$, did not like Blackboard specifically. The reasons that were listed for not liking Blackboard .included not being able to find what they needed, the system always seeming to be down, not being kept up-to-date, and the information being unorganized and confusing [6].

The Board wanted to determine the perceived faults and drawbacks of using Blackboard. The major drawbacks were determined to be the lack of knowledge possessed by the course professors, the inconsistent nature of how Blackboard is utilized at the University, and that instructors rely too much on Blackboard to teach the classes. The students also reported having technical issues and disliked having to print out material [6]. 
The final area of the study asked students to pick one feature of Blackboard that they would like to see changed. The students wanted their professors to send them an email every time new content was added. They also wanted the Digital Dropbox to be simplified; the Digital Dropbox is the tool that allows students to submit their assignments. Other features that needed improvement included email and the discussion board interface. Lastly the students were asked to identify features or tools that they would like to be used in Blackboard. These features included improved email, a notification system, access to the class roster, and a course calendar. Some of the tools that the students wanted to be added to Blackboard were already in place, leaving the board to assess if the features were not obvious as they should be to the users [6]. This lack of knowledge could be addressed by brief just-in-time training.

\section{PURPOSE OF THE STUDY}

Distance learning enables Universities to reach students all over the world. The online environment offers unique advantages over traditional learning environments; it allows students to access the classes at their convenience day or night. The purpose of the study is to examine student's perceptions of using the Blackboard online learning management tool. This study explores the following research questions:

RQ1: What is the basis for the student's choice of classroom format?

RQ2: What are the reasons for the student's satisfaction with Blackboard?

RQ3: What are the benefits and drawbacks of courses that use Blackboard?

\section{RESEARCH METHODOLOGY}

This study examined student perceptions of using Blackboard, an online learning management tool, at a small rural Mid-Atlantic University during March 2010. A quantitative methodology was selected for this study as a means to assess the student's use of Blackboard. The population chosen for the student survey was comprised of undergraduate and graduate students at a small rural Mid-Atlantic University.

Undergraduate and graduate students were surveyed in order to gather data from students 18 years of age or older. The survey was administered using Survey Monkey, an online survey tool, to 9,017 students from March 18, 2010 through March 31, 2010. A total of 100 students completed the survey. The students surveyed consisted of residential and nonresidential students.
Survey questions administered to University students focused on obtaining information from students who have used Blackboard. The majority of the survey was a partial replication of a 2006 [6] Blackboard Student Survey Report conducted at the University of Denver. Additional questions were developed by the researchers. The survey results were analyzed using SPSS statistical software. This study used Chi-square with a statistical significance at the .05 margin of error with a $95 \%$ confidence level to determine student's perception of Blackboard. Statistical frequencies were used to determine the basis for the student's use of Blackboard, as well as, the benefits and drawbacks of using the online assessment tool. The study was a convenience sample surveying students from the School of Arts and Humanities, Business, Science and Math, Engineering, Computer Science, Information Technology, and Psychology

The survey instrument consisted of 15 closed-ended questions and 1 open-ended question. Seven of the closed-ended questions provided an "Other" option, which allowed students to provide responses in addition to predetermined responses listed in each question. The first four questions focused on student demographics; they included, gender, age, education and degree program. Question five, a contingency question, asked students if they have taken any online distance learning classes. If the students answered yes, they continued to question six which asked if they had used Blackboard. If the students answered yes again, they were to continue with the survey. If the answer was no, they were to stop answering the questions and exit the survey. Based on the participant's knowledge and use of Blackboard, questions 7-9 focused on the tools and features used. Questions 10-12 were developed in order to assess student's satisfaction with Blackboard. Questions 1315 addressed the benefits and drawbacks of using the online assessment tool. The final question was designed so that students could give an open-ended response about the features that they would like to see used or added to Blackboard.

\section{RESULTS}

The survey responses were analyzed to determine the basis for their choice of instructional format, the reasons for satisfaction, and the benefits / drawbacks of using Blackboard. The overall student responses indicated that $65 \%$ of the respondents were female and $35 \%$ of the respondents were male. The demographic and background information was further detailed in relation to gender in Figure 1 and 
Table 1. Figure 1 breaks down the percentage of males and females that are illustrated according to their education level. The senior and junior standing students for both males and females had the highest response rate. Table 1 illustrates the percentage of students for each gender in relation to age, education level, desired degree, and their prior experience with having taken online classes before.

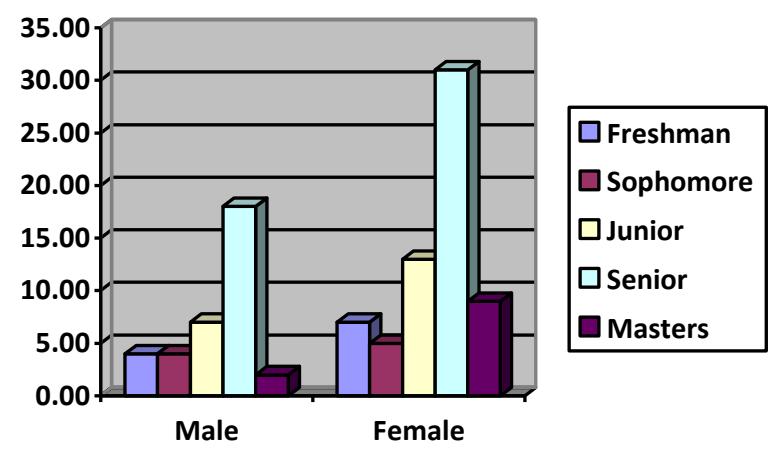

Figure 1: Education Level Broken Down by Gender

Table 1: Demographic Breakdown of Survey Participants

\begin{tabular}{|c|c|c|}
\hline $\begin{array}{l}\text { Demographic } \\
\text { Information }\end{array}$ & Male & Female \\
\hline \multicolumn{3}{|l|}{ Age: } \\
\hline $18-25$ & $20 \%$ & $35 \%$ \\
\hline $26-35$ & $4 \%$ & $9 \%$ \\
\hline $36-45$ & $7 \%$ & $11 \%$ \\
\hline $46-55$ & $2 \%$ & $9 \%$ \\
\hline $56-65$ & $2 \%$ & $1 \%$ \\
\hline \multicolumn{3}{|l|}{ Education Level: } \\
\hline Freshman & $4.0 \%$ & $7.0 \%$ \\
\hline Sophomore & $4.0 \%$ & $5.0 \%$ \\
\hline Junior & $7.0 \%$ & $13.0 \%$ \\
\hline Senior & $18.0 \%$ & $31.0 \%$ \\
\hline Masters & $2.0 \%$ & $9.0 \%$ \\
\hline \multicolumn{3}{|l|}{ Degree: } \\
\hline Arts and Humanities & $3.1 \%$ & $6.2 \%$ \\
\hline Business & $17.1 \%$ & $21.6 \%$ \\
\hline Education & $1.0 \%$ & $17.5 \%$ \\
\hline Science \& Math & $3.1 \%$ & $9.3 \%$ \\
\hline Engineering & $8.2 \%$ & $0.0 \%$ \\
\hline Computer Science & $0.0 \%$ & $1.0 \%$ \\
\hline Information & $1.0 \%$ & $1.0 \%$ \\
\hline Technology & $0.0 \%$ & $7.2 \%$ \\
\hline Psychology & $0.0 \%$ & $2.1 \%$ \\
\hline \multicolumn{3}{|l|}{ Undecided } \\
\hline \multicolumn{3}{|l|}{ Online Classes Before } \\
\hline Yes & $28 \%$ & $54 \%$ \\
\hline No & $7 \%$ & $11 \%$ \\
\hline Total & $35 \%$ & $65 \%$ \\
\hline
\end{tabular}

Volume XI, No. 1, 2010

\section{Basis for Classroom Format}

Survey question number five asked if the students had taken an online class before. If they answered "yes," they were prompted to complete the remainder of the survey which included questions about the instructional format. If they answered "no", they received a "Thank You for Participating" message and did not complete the remainder of the survey. The rationale for not allowing the students who answered "no" to complete the study was because the remaining questions were focused on assessing a user's experience and perception of Blackboard.

Of the 100 respondents who started the survey, 81 answered "yes," and 18 answered "no." One student did not answer this question and based upon the missing responses for the remaining questions of this student, it can only be assumed that the student exited the survey at that point. The following question prompted the students to choose their preferred instructional format; $36 \%$ of the students chose "Online," 29\% chose "In the Classroom", and 35\% chose "Blended." The respondents were then asked to identify reasons for their instructional format choice and were allowed to select more than one response. The following reasons were selected as the most popular for each of the Instructional formats: Time Constraints for Online Classes, Learning Effectiveness for In the Classroom and Learning Effectiveness for Blended. Table 2 identifies additional reasons for each of the instructional formats. Each of the values in the table represents the number of respondents who selected that respective reason. None of the students responded with the answer "Other" providing additional reasons for their format preference.

Table 2: Students' Reasons for Specific Instructional Format

\begin{tabular}{|c|c|c|c|c|}
\hline $\begin{array}{l}\text { Format } \\
\text { Reasons } \\
\end{array}$ & Online & $\frac{\text { In The }}{\text { Classroom }}$ & Blended & $\underline{\text { Total }}$ \\
\hline Faculty & 3 & 14 & 16 & 33 \\
\hline Format & 10 & 12 & 9 & 31 \\
\hline $\begin{array}{l}\text { Time } \\
\text { Constraints }\end{array}$ & 28 & 5 & 19 & 52 \\
\hline $\begin{array}{l}\text { Learning } \\
\text { Effectiveness }\end{array}$ & 4 & 21 & 20 & 45 \\
\hline Pedagogy & 1 & 4 & 0 & 5 \\
\hline Accessibility & 17 & 6 & 11 & 34 \\
\hline Privacy & 2 & 0 & 1 & 3 \\
\hline $\begin{array}{l}\text { Learning } \\
\text { Style }\end{array}$ & 16 & 23 & 19 & 58 \\
\hline Community & 0 & 8 & 11 & 19 \\
\hline
\end{tabular}




\section{Reasons for Satisfaction}

The next series of questions focused on student satisfaction with the functionality of Blackboard. If they answered "yes," the students were prompted to mark all the reasons that led to their satisfaction with Blackboard. Students that answered "no" were prompted to select responses regarding their lack of satisfaction if they answered "no." Of the 80 respondents, $89 \%$ (71 Students) answered that they were satisfied with the functionality of Blackboard and $11 \%$ (9 Students) answered they were not satisfied with the functionality of Blackboard.

The ten items in Table 3 were identified by $89 \%$ of the respondents (71 students) as reasons for the students' satisfaction. The most popular reason was Blackboard's 24/7 availability. The second popular reason was that Blackboard facilitates learning. Blackboard's interoperability was the least popular reason. There were no valid responses that were entered as "Other."

Table 3: Responses for Satisfaction

\begin{tabular}{lr}
\hline Satisfaction & $\underline{\text { Total }}$ \\
\hline It provides 24/7 access to class material & $95.8 \%$ \\
\hline Ease of use & $73.2 \%$ \\
It facilitates learning & $49.3 \%$ \\
\hline $\begin{array}{l}\text { It improves communication with the } \\
\text { Instructor }\end{array}$ & $35.2 \%$ \\
It improves communication with fellow & \\
students & $35.2 \%$ \\
It Helps me Learn How to use technology & $25.4 \%$ \\
It facilitates collaboration on group & \\
projects & $23.9 \%$ \\
\hline Small learning curve & $21.1 \%$ \\
Intuitive & $15.5 \%$ \\
\hline Interoperability & $7.0 \%$ \\
\hline
\end{tabular}

On the other hand, nine students responded that they were dissatisfied with the functionality of Blackboard. Table 4 summarized the responses for the students' dissatisfaction with Blackboard. The unanimous response among all nine students was that the Blackboard sites were not kept up-to-date. Other reasons for dissatisfaction with Blackboard's functionality were that students had a difficult time teaming online and that they felt the interface was poorly designed. The least favored response was that Blackboard had a Large Learning Curve. The remaining responses are documented in Table 4.
Table 4: Responses for Dissatisfaction

\begin{tabular}{lr}
\hline I don't like Blackboard because: & Total \\
\hline It is very rarely kept up-to-date & $100.0 \%$ \\
\hline I can't team properly online & $77.8 \%$ \\
\hline Poorly designed interface & $77.8 \%$ \\
\hline Can't find what I am looking for in \\
Blackboard & $55.6 \%$ \\
It is unorganized and confusing & $55.6 \%$ \\
I don't like to spend time online & $44.4 \%$ \\
Not Intuitive & $33.3 \%$ \\
Hard to navigate & $33.3 \%$ \\
\hline It never works properly & $22.2 \%$ \\
\hline
\end{tabular}

Eight students provided additional comments beyond the predefined responses that were presented. These responses were grouped as either reasons associated with the application or reasons associated with the instructor. Two students identified issues related to the application. One student mentioned that the application disconnects students from the instructor while another mentioned that the application does not provide a great means of communication with other students in the class. Six students mentioned that their dissatisfaction was related to something that is controlled by the instructor. Of the six, two students mentioned that it was easy to forget about assignments using blackboard, whereas they don't' forget when they have a weekly class. Two other students mentioned that the class specific Blackboard shell seemed disorganized. Three other students mentioned reasons such as faculty lacking knowledge with Blackboard, faculty unable to properly use Blackboard, and method faculty chose to conduct exams on blackboard.

\section{Benefits and Drawbacks}

The remaining survey questions inquired about the perceived benefits and drawbacks about Blackboard. The highest ranked benefits identified by the students included checking grades, access to course materials, and overall accessibility to the Blackboard system. The least ranked responses to benefits included teaming activities such as enhancing team cohesiveness and collaborative group projects. The responses to the perceived benefits of Blackboard are documented in Table 5. 
Table 5: Benefits of Blackboard

\begin{tabular}{lc}
\hline I like Blackboard because: & Total \\
\hline Checking Grades & $96.3 \%$ \\
\hline Ease of access to course materials & $88.8 \%$ \\
\hline Accessibility & $70.0 \%$ \\
Promote group discussion & $33.8 \%$ \\
Quality of assessments & $27.5 \%$ \\
\hline Access to the instructor & $26.2 \%$ \\
Solicit feedback from peers and the & $23.8 \%$ \\
instructor & $10.0 \%$ \\
\hline Enhance team cohesiveness & $6.3 \%$ \\
\hline Collaborative group projects
\end{tabular}

Based upon the Blackboard Student Survey Report in 2006 [6], the survey allowed students to identify the potential drawbacks of using Blackboard. The two highest ranked drawbacks are a lack of standardization in Blackboard and that professors do not use Blackboard effectively. Other drawbacks were identified as issues with access/technology and that students must print out the course documents for their reference. All of the drawbacks are summarized in Table 6. Two students provided an additional response after selecting "Other." The first student explained that it is difficult to explain unclear assignments and receive feedback using Blackboard. Another student mentioned that sometimes the instructor will intentionally make the online class harder using Blackboard simply because the class is online and not in a traditional classroom setting.

Table 6: Drawbacks of Blackboard

\begin{tabular}{lr}
\hline Drawbacks & \multicolumn{1}{c}{ Total } \\
\hline $\begin{array}{l}\text { Inconsistent use of Blackboard by } \\
\text { instructors }\end{array}$ & $66.3 \%$ \\
$\begin{array}{l}\text { Professors don't know how to use it } \\
\text { effectively }\end{array}$ & $50.0 \%$ \\
Not used to its potential & $47.5 \%$ \\
Problems with technology/access issues & $32.5 \%$ \\
\hline Have to print everything yourself & $20.0 \%$ \\
\hline
\end{tabular}

\section{LIMITATIONS}

While this study received a number of responses to the survey, it had a few limitations that could have impacted the findings. The first is that the response rate was low in comparison to what was expected. The second limitation dealt with how the students were notified. Instead of each student receiving an email specific to this study, they received one daily announcement email that encompassed this request and others. This communication method was a recent standardization at the university instead of the students receiving multiple email announcements in a single day. It can be assumed that students may have ignored the announcement email and therefore never seen the request to participate in the study. The last limitation was that the survey was sent out after spring break when certain professors schedule their midterm exams. Because of the time commitment with the exam, students may not have had an opportunity to complete the survey.

\section{CONCLUSIONS}

This research was a partial replication of a study conducted by the University of Denver [6] in 2006 with modifications that applied to the university under study. Our survey was intended to capture the student's preference for instructional format, the basis for choosing this format, their reasons for satisfaction / dissatisfaction with Blackboard, and their perceived benefits / drawbacks of Blackboard. The survey concluded that $66 \%$ of all participants preferred an instructional format with some online presence using Blackboard.

Students who chose the online format responded that they prefer online classes because it addressed their time constraints, it was easily accessible, and used a learning style that was appropriate for them. The classroom format was chosen by other students because of its learning style and the faculty presence. The blended instructional format shared the similar responses as students who chose the online instructional format. While the overall basis for students to choose their preferred instruction format varied, it is important to note that learning style was one of the primary drivers for each of the students' choices for their instructional format.

The overall response of the students was that the majority were satisfied with the use of Blackboard for online classes. The results illustrated that the students were most pleased with Blackboard because it provided 24/7 availability, it facilitating learning, and enhanced communication with professors / students. These results were similar to those found in the Blackboard Student Survey Report in 2006 [6] conducted by the University of Denver. On the other hand, approximately $11 \%$ of the respondents were not satisfied with Blackboard; they were unanimous in their responses that the Blackboard sites were not 
kept up-to-date. This result is also correlated to a previous question where faculty ranked low as the basis for students to take online classes. These two results were linked since in most cases faculty is responsible for maintaining and keeping their Blackboard sites up-to-date.

Students found that the overall accessibility of Blackboard to check for grades and course materials to be the primary benefits Blackboard has to offer them. These results were also correlated with the results of why students were satisfied with Blackboard. The primary reason for students' satisfaction with Blackboard was that it was available 24/7 which allows students to access their grade information and course materials at any time. The alternative to this would be for students to email or contact their instructor but that would take away the benefit of obtaining this information quickly and whenever they need it.

The acceptance of technology is important for the success of the technology. In the case of Blackboard at this university, the students identified many benefits and the majority of the respondents were satisfied with the application. However, no technology is perfect. Based upon the drawbacks and reasons for dissatisfaction by a small percentage of the students, the university can modify its Blackboard environment and provide training to faculty and students to ensure that the application is used as it is intended.

\section{REFERENCES}

1. Blackboard Inc. (2000). Educational benefits of online learning. A Blackboard tip sheet.

Retrieved on February 26, 2010 from http://med.uth.tmc.edu/administration/edu_progr ams/ep/blackboard/text/Online_Learning_Benefi ts.pdf

2. Dorado, C., Hernandez, J., Sani, B,. Griffin, C. \& Barnett, W. (2009) An exploratory analysis of factors influencing students decisions to take online courses. Issues in Information Systems. Vol. X. (1) 2009.

3. Greer, J. (2009, January 26) Study:Online education continues its meteoric growth. U.S. News and World Report. Retrieved on March 15, 2010 from http:/www.usanews.com/articles/educationonline-education/2010/10/26study-onlineeducation-continues-to-grow
4. Hannay, M., Newvine, T. (2006). Perceptions of Distance Learning: A comparison of online and traditional learning. Merlot Journal of Online Learning \& Teaching. 2,(1) March 2006, 1-11.

5. Lonn, S., \& Teasley, S. (2009) Saving time or innovating practice: Investigating perceptions and uses of Learning Management Systems. Computer \& Education, 53(3), 686-694. doi: 10.1016/j.compedu.2009.04.008

6. The Center. (2006). Blackboard student survey report Winter 2006. The Center for Teaching \& Learning at the DU Faculty Advisory Board.

7. Smart, K., \& Cappel, J.J,. (2006) Students' perceptions of online learning: A comparative study. Journal of Information Technology Education. 1 (5), 202-219

8. Volery, T. \& Lord, D. (2000) Critical success factors in online education. The International Journal of Education Management. 14(15\%, 216-223. 